\title{
Health Targets in the Former Soviet Countries: Responding to the NCD Challenge?
}

\author{
Ketevan Glonti, MSc, ${ }^{1}$ \\ Bernd Rechel, MA, $\mathrm{PhD}^{2}$
}

\begin{abstract}
This article examines health target-setting in 12 former Soviet countries: Armenia, Azerbaijan, Belarus, Georgia, Kazakhstan, Kyrgyzstan, Moldova, Russia, Tajikistan, Turkmenistan, Ukraine, and Uzbekistan. We explored which health targets were set out in national health strategies and within the context of the United Nations initiative on the Millennium Development Goals (MDGs). We found that few former Soviet countries embraced health targets in national health strategies that were quantitative and time-bound. In contrast, measurable and time-bound targets were adopted by almost all countries in the region within the MDG initiative. As the MDG initiative failed to reflect the considerable burden of non-communicable disease in the region, and focussed entirely on communicable disease and mother and child health, this meant that health targets were missing for one of the most severe health challenges in the former Soviet countries. The quality of health data that could guide national health policies is another major challenge for the control of both communicable and non-communicable disease, as well as improvements in mother and child health.
\end{abstract}

Key Words: Health targets, health indicators, Millennium Development Goals, Commonwealth of Independent States, Eastern Europe

Recommended Citation: Glonti K, Rechel B. Health targets in the former Soviet countries: responding to the NCD challenge? Public Health Reviews. 2013;35: epub ahead of print.

\footnotetext{
${ }^{1}$ London School of Hygiene and Tropical Medicine, London, UK.

${ }^{2}$ European Observatory on Health Systems and Policies, London School of Hygiene and Tropical Medicine, London, UK.

Corresponding Author Contact Information: Ketevan Glonti at ketevan.glonti@1shtm. ac.uk; London School of Hygiene and Tropical Medicine, 15-17 Tavistock Place WC1H 9SH, UK.
} 


\section{INTRODUCTION}

The purpose of health targets is to improve population health through more rational and transparent health policy. Health target-setting is generally a step-by-step process, starting with general principles and values, and leading to long-term goals. Goals can be further specified in objectives, resulting in measurable and time-bound qualitative or quantitative targets. ${ }^{1}$ Targets are distinct from health indicators. The latter simply measure current health status, whereas targets imply a political decision to take action and achieve improvements of indicators. ${ }^{2}$

The World Health Organization (WHO) first introduced the concept of health targets in its global 1981 Health for All strategy, adapting the targets in 1984 to the WHO European region. ${ }^{3}$ Ideally, health targets should be SMART: specific (setting out the target to be met); measurable (allowing it to be monitored); accurate (ensuring that fulfilment is recognizable); realistic (challenging, but achievable) and time-bound (with a clear time frame). ${ }^{4}$ Establishing health targets requires appropriate and accurate health data.

Health targets often depend on routine data reported to international health databases, such as WHO's European Health for All Database (itself an outcome of the Health for All strategy), as well as other regular sources of information, such as annual health surveys. Ideally, data collection is followed by data analysis, continuous monitoring and evaluation of progress. In order to successfully implement health targets, the collaboration of key actors and the development of ownership and accountability are essential. ${ }^{5}$ All of this requires adequate funding. Thus, health targets are only useful and achievable if they are SMART, embedded in an overarching, long-term health strategy, accepted by stakeholders at all levels and sufficiently funded. ${ }^{6}$

Health targets have been adopted by many European countries, but with greatly varying degrees of success. ${ }^{7}$ The challenges have been especially great for the 12 former Soviet countries of Armenia, Azerbaijan, Belarus, Georgia, Kazakhstan, Kyrgyzstan, Moldova, Russia, Tajikistan, Turkmenistan, Ukraine, and Uzbekistan. ${ }^{8}$ It is the latter countries, by current Western standards characterized by a deficiency of health policy and planning, ${ }^{9}$ that are the focus of this article.

In the Soviet period, health targets were vague and unspecific, mostly based on ideological principles and enshrined in successive five-year plans. The focus was on inputs rather than outputs,,$^{10}$ in particular quantitative measures such as increased numbers of hospital beds and health workers. ${ }^{11}$ After the dissolution of the Soviet Union, the newly independent states 
gradually started to restructure their health systems and develop new health strategies, often supported by external agencies, such as WHO, the World Bank and a range of bilateral donors. ${ }^{12}$

This article provides a comparative overview of the current state of health targets in the 12 former Soviet countries that have remained outside the European Union. It is based on a review of the academic literature, the Health Systems in Transition (HiT) country profiles produced by the European Observatory on Health Systems and Policies for each of the 12 countries, the WHO health system performance assessments (available for Georgia and Armenia), the United Nations website for Millennium Development Goal (MDG) indicators, ${ }^{13}$ as well as national MDG progress reports.

We first explore the Soviet practice of health target-setting prior to the USSR's dissolution in 1991, which helps to understand current challenges in health target-setting. We then examine post-Soviet experiences, providing comparative information on target-setting in each of the 12 countries. This is followed by a discussion of data quality and some concluding observations.

\section{HISTORICAL BACKGROUND: SOVIET PRACTICES PRIOR TO 1991}

Lenin's famous remark: "If socialism cannot conquer the lice, then the lice will conquer socialism" 14 referred to the threat that recurrent epidemics of communicable disease-including typhus, dysentery and smallpox-posed to the stability of the newly established Soviet regime ${ }^{15}$ Creating a universal health system geared towards eradicating communicable disease was a priority on the Bolsheviks' agenda. ${ }^{16}$ Health care was seen as a public good and every citizen's right; it strived to be egalitarian. ${ }^{17}$ Improved population health was also important for an efficient and functioning labour force for the industrialization of the country between the two World Wars. ${ }^{18}$ Health care became highly centralized, tax-funded and entirely provided by the state. The way forward to tackle communicable disease was first outlined in 1924 in an article by Nikolai Semashko, the first People's Commissar for Public Health. Semashko presented a mission statement and objectives of the sanitary epidemiological (san-epid) service, giving direction to the development of the Soviet health system in subsequent years. The san-epid service developed into an extensive network of public health centers distributed throughout the entire Soviet Union. It was tasked with gathering and analyzing epidemiological data, with the aim of preventing and 
eradicating communicable disease through preventive interventions such as vaccination. ${ }^{16}$

Clinical care was largely provided in hospitals. Primary health care, in urban areas provided by polyclinics and in rural areas by ambulatory facilities and feldsher-midwifery points, had a lower status and offered poorer levels of care. ${ }^{8,19-21}$ From the 1930s onwards, medical education was no longer provided by universities, but by institutes established and controlled by the Ministry of Health, undermining the quality of medical education. ${ }^{22}$ Furthermore, professional medical associations had been abolished and a quality control system for health care providers was lacking. ${ }^{23,24}$ Professionals had no access to the international scientific literature; the small number of domestic journals was obliged to publish in strict conformance with communist ideals and slogans, and censorship was rife. ${ }^{25}$

The responsibility for health target-setting in the Soviet Union was entirely in the hands of the Central Committee of the Communist Party, a small elite group operating from Moscow. ${ }^{25}$ In addition, all health-related data, passed onto and processed by the State Committee for Statistics (Goskomstat), were known to be unreliable, partly due to severe punishments if data did not conform to expected outcomes. Targets were non-specific, based on successive five-year plans, and did not take into account existing evidence. ${ }^{11}$

By the 1960s, the Soviet system had brought many communicable diseases under control. This achievement was possible due to the high priority given to communicable disease control, relatively straightforward and easily delivered interventions (such as vaccinations), and the nature of the regime, which facilitated country-wide compliance. ${ }^{15,25}$ Subsequently, much less attention was paid to health-related issues, as demonstrated by low levels of government funding to health. ${ }^{26}$ In fact, the health status of the population notably worsened from the 1960 s onwards ${ }^{27}$ Officially recorded infant mortality increased from 22.9 per 1,000 live births in 1971 to 26 in 1985, even though the Soviet definition of live birth undercounted infant mortality. ${ }^{28,29}$ Furthermore, the cardiovascular disease burden increased dramatically after the 1960s and there was also a surge in alcohol consumption. ${ }^{28}$ The epidemiologic transition from communicable to noncommunicable disease ${ }^{30}$ was recognized, but the Soviet health system was poorly positioned to respond to it. ${ }^{22}$

With only 4.5 percent of the state budget allocated to health in 1985 , the health system was underfunded and heavily neglected. Although health services were nominally free at the point of use, the underfunding of the 
system, characterized by low salaries and lack of medication, had made it impossible to keep health care free in practice, giving rise to informal payments. ${ }^{24}$ At the same time, parallel (or "closed") health systems were in place, in which elite government employees, as well as those from certain industries, were entitled to better funded health care of higher quality. This exacerbated inequalities and inefficiencies in health care provision. ${ }^{28}$ Staff numbers were high, but health workers lacked sufficient training, sophisticated equipment and adequate working conditions. ${ }^{31}$ When Gorbachev came to power in 1985, the shortcomings of the Soviet health system were for the first time openly addressed in public. The policy calling for increased transparency-Glasnost-eventually led to restructuring attempts-Perestroika. ${ }^{28}$

\section{POST-SOVIET HEALTH TARGET-SETTING}

After the Soviet Union broke apart, each of the former federal Ministries of Health became responsible for health policy and planning. They often lacked technical capacity for doing so and were confronted with the Soviet legacy of an oversized network of health facilities, as well as the transitional crisis in which government expenditure for health plummeted. The countries gradually embarked on health reforms in the 1990s, but often retained many features of the Soviet system. All aimed to strengthen primary health care and to downsize the hospital sector, and many introduced health insurance systems. ${ }^{8}$ Decentralization was another common element of reforms in several countries, and there are also attempts to reorganize public health services. ${ }^{32}$ International agencies, such as the World Bank and WHO, as well as various bilateral partners, assisted in reform efforts. ${ }^{10}$

Health reform efforts were, to various degrees, guided by national health strategies. However, most strategies failed to have clear health targets. Armenia currently lacks a national health strategy, although a working document has been published. By contrast, Tajikistan's 2002 Health Care Strategy outlined seven clearly defined targets to be achieved within a specified timeframe. ${ }^{33}$ Kazakhstan's national health strategy also set out a series of clearly defined and time-bound health targets. ${ }^{34}$ Russia's health policy aims to increase life expectancy to 75 years by 2020. In the remaining eight countries, the health targets included in national health strategies were formulated in qualitative terms and often did not have a clear timeframe (Table 1). 


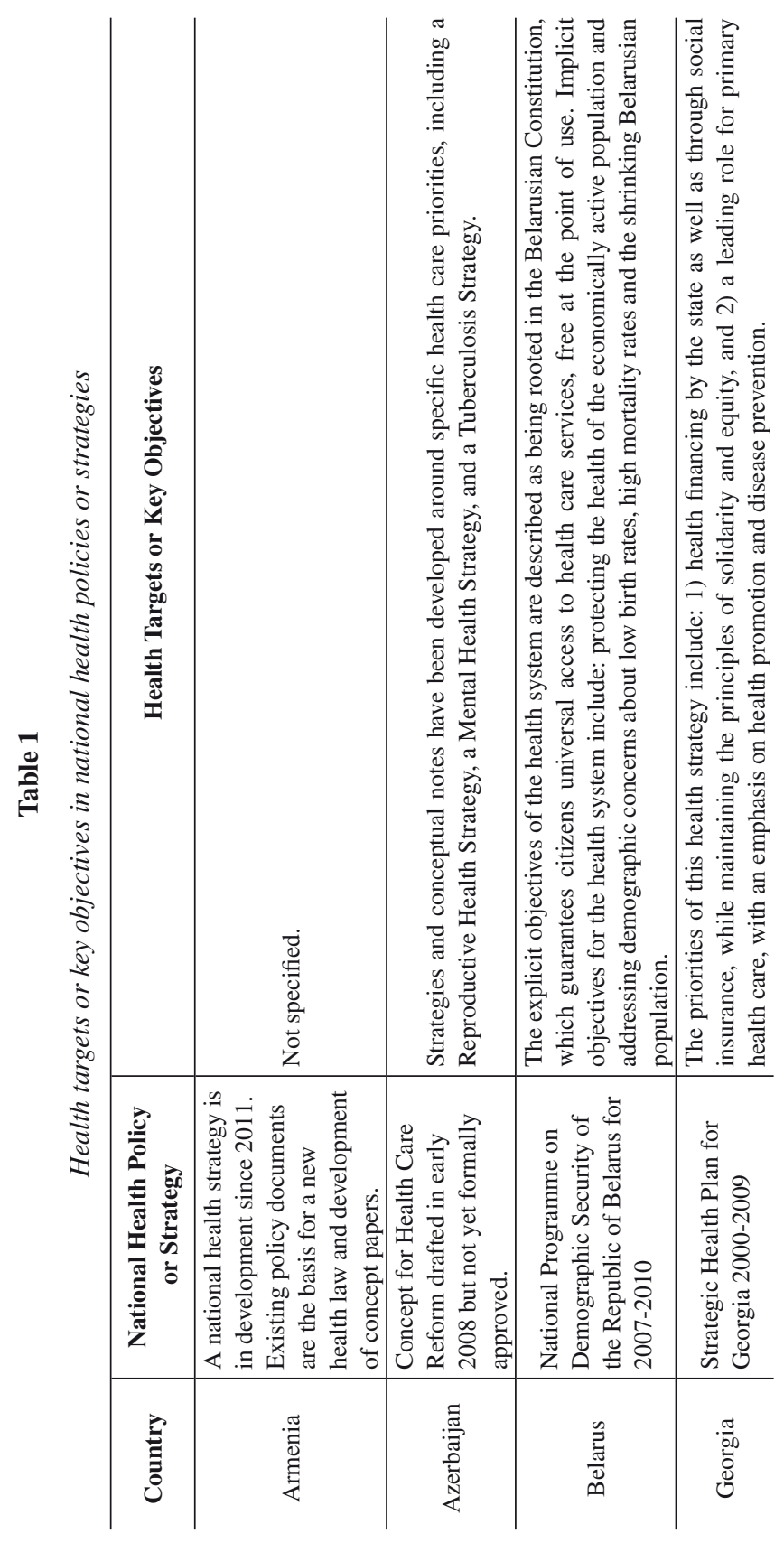




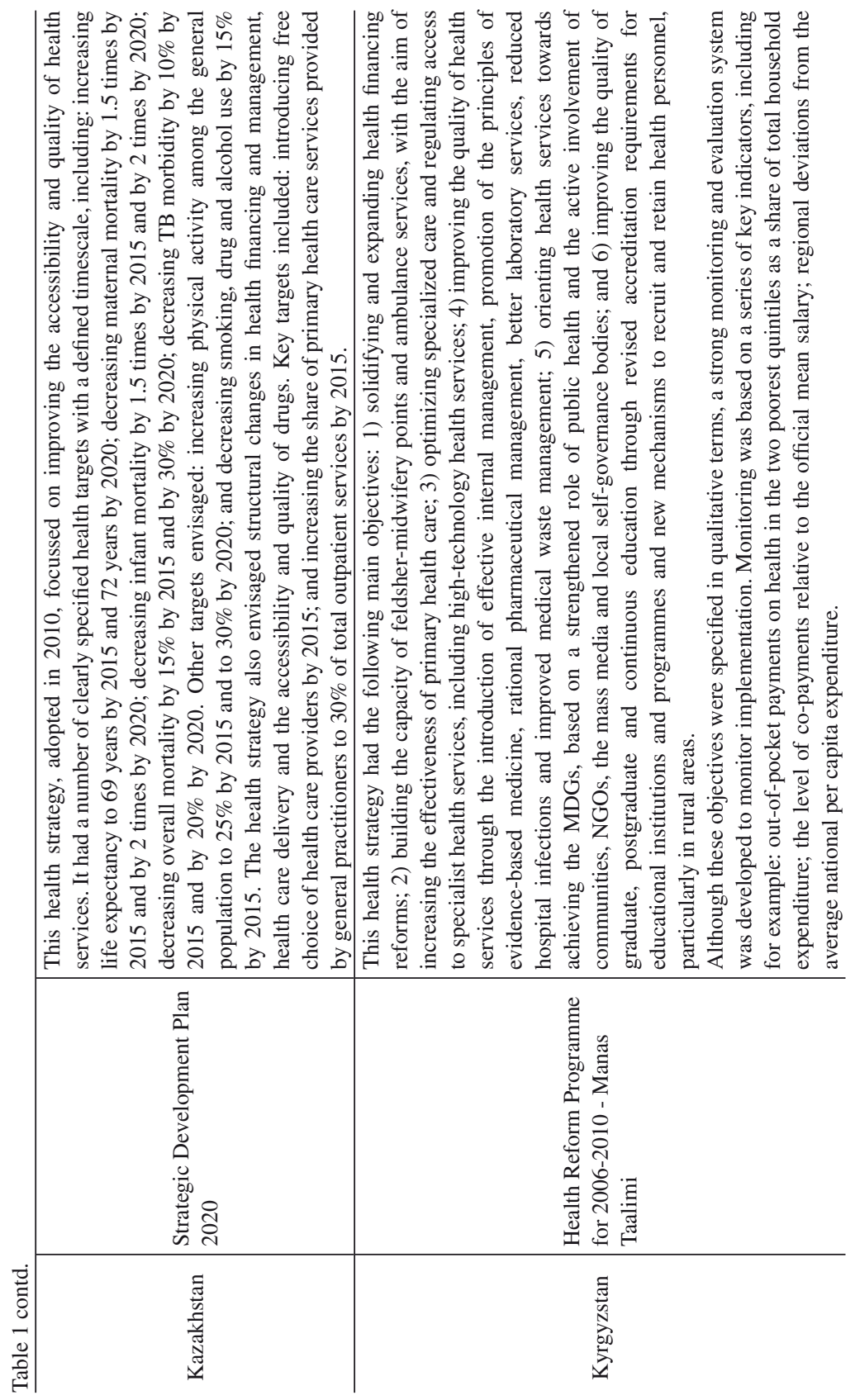




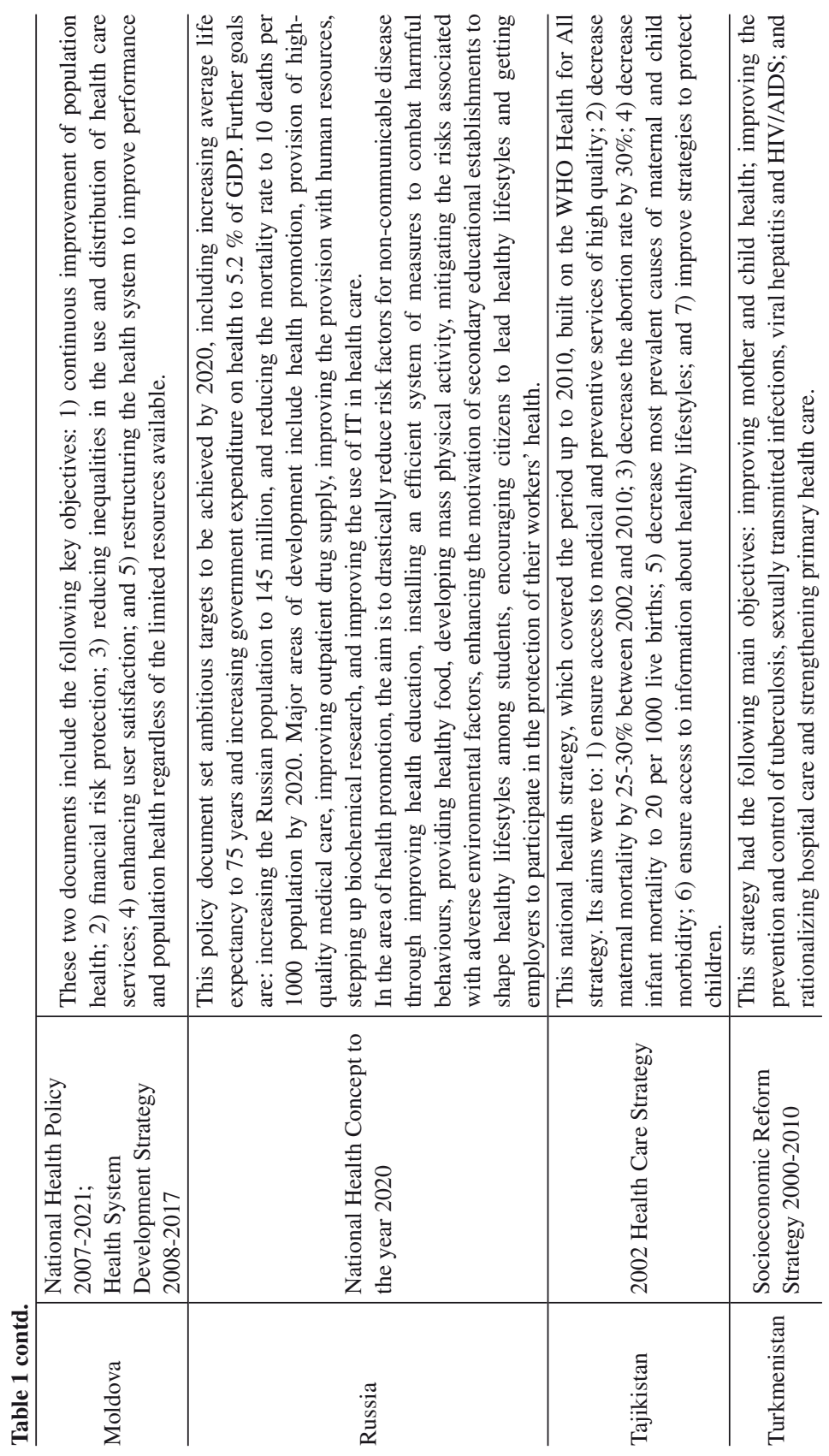




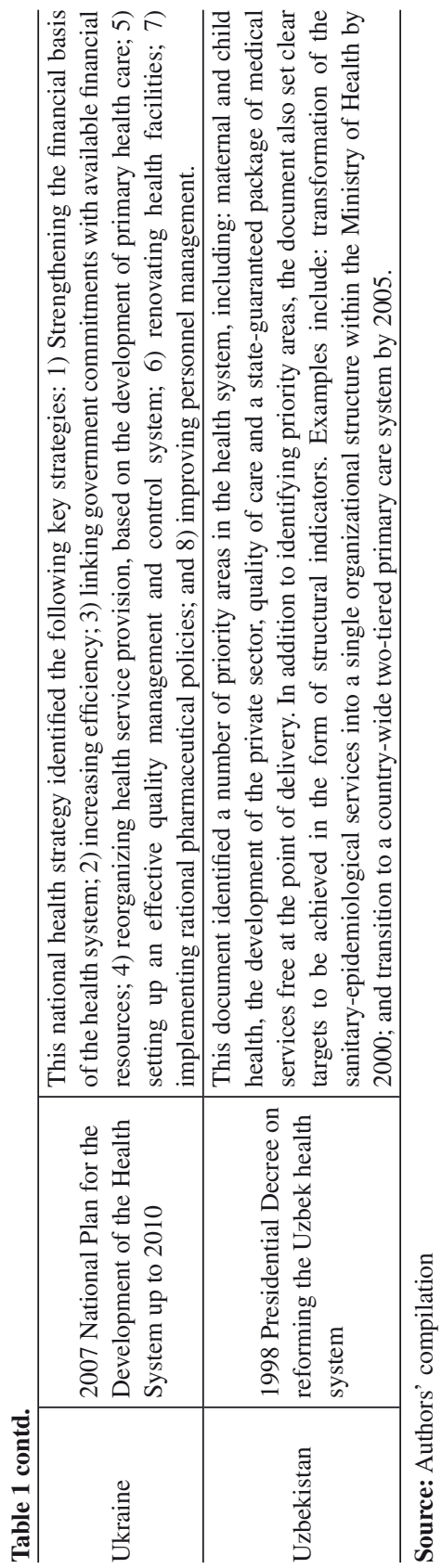




\section{HEALTH TARGETS WITHIN THE MDG INITIATIVE}

In striking contrast, almost all of the 12 countries have been involved in setting quantitative and time-bound health targets as a result of the MDG initiative, originating from the UN Millennium Declaration, signed in 2000 by 189 countries. ${ }^{35}$ Three of eight development goals (Goals 4, 5 and 6) are directly concerned with health, targeting child mortality, maternal health, and HIV/AIDS, malaria and "other diseases". They are further specified in seven health targets and 19 corresponding indicators, with a further disaggregation expected by sex and locality.

Relevant data are collected nationally and submitted through progress reports to the UN, which processes and publishes the data. The UN website specifies whether data have been produced and reported by the country, estimated by the agency (in case of lack of reporting, when country data are not available, where there are multiple sources or issues with data quality), or produced by the country and adjusted by the agency for international comparability. ${ }^{36}$

Table 2 illustrates whether countries have adopted the original MDG targets and indicators and shows the baseline health indicators that have been used. Due to missing UN estimates, Moldova is not presented in the table. We also excluded targets on malaria, as it is not a major health concern for most of the countries discussed here.

We found that most countries had adapted all or some MDG targets and their associated progress measurement indicators. Armenia, Kazakhstan and Kyrgyzstan are exceptions, in that they adopted the majority of MDG targets and indicators in their original form..$^{37-39}$ Several countries adopted a baseline year different from 1990, ranging from 1995 to 2006, in view of political instability and lack of reliable data during the early years of transition. This was the case for Azerbaijan, Georgia, Moldova, Turkmenistan, Ukraine and Uzbekistan. ${ }^{40-45}$

Significant discrepancies emerge between data reported by national authorities as compared to those reported by international agencies. For example, the Armenian MDG progress report noted that infant mortality was 23.8 in 1990; however, the official UN site for the MDG indicators indicates that it was 47.2, allegedly based on country-level data. High discrepancies can also be observed in maternal mortality (e.g., for Kazakhstan, Russia and Turkmenistan). Interestingly, in the case of countries that have adopted the MDGs with minimal or no modification (Armenia, Kazakhstan and Kyrgyzstan), discrepancies are among the highest. 


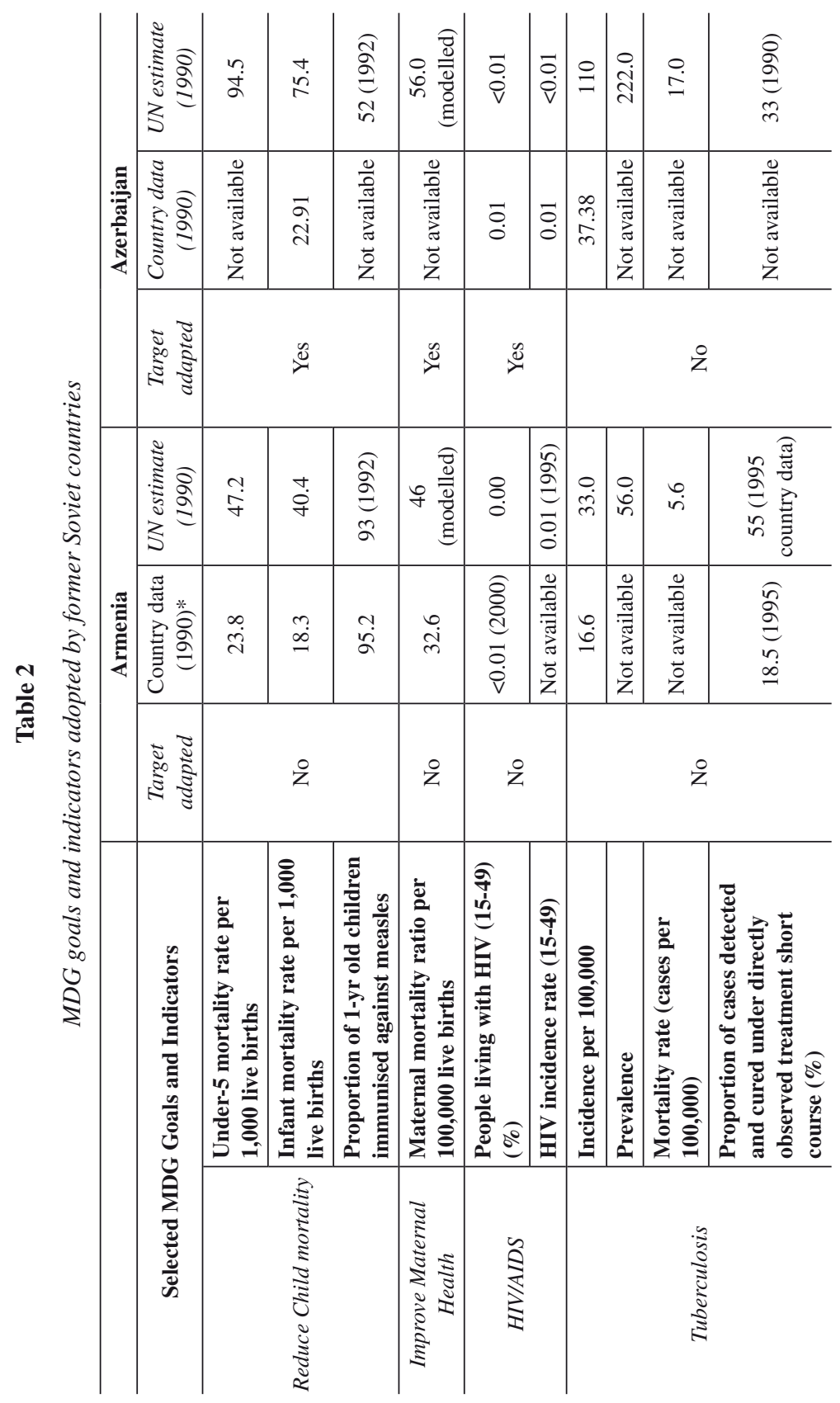




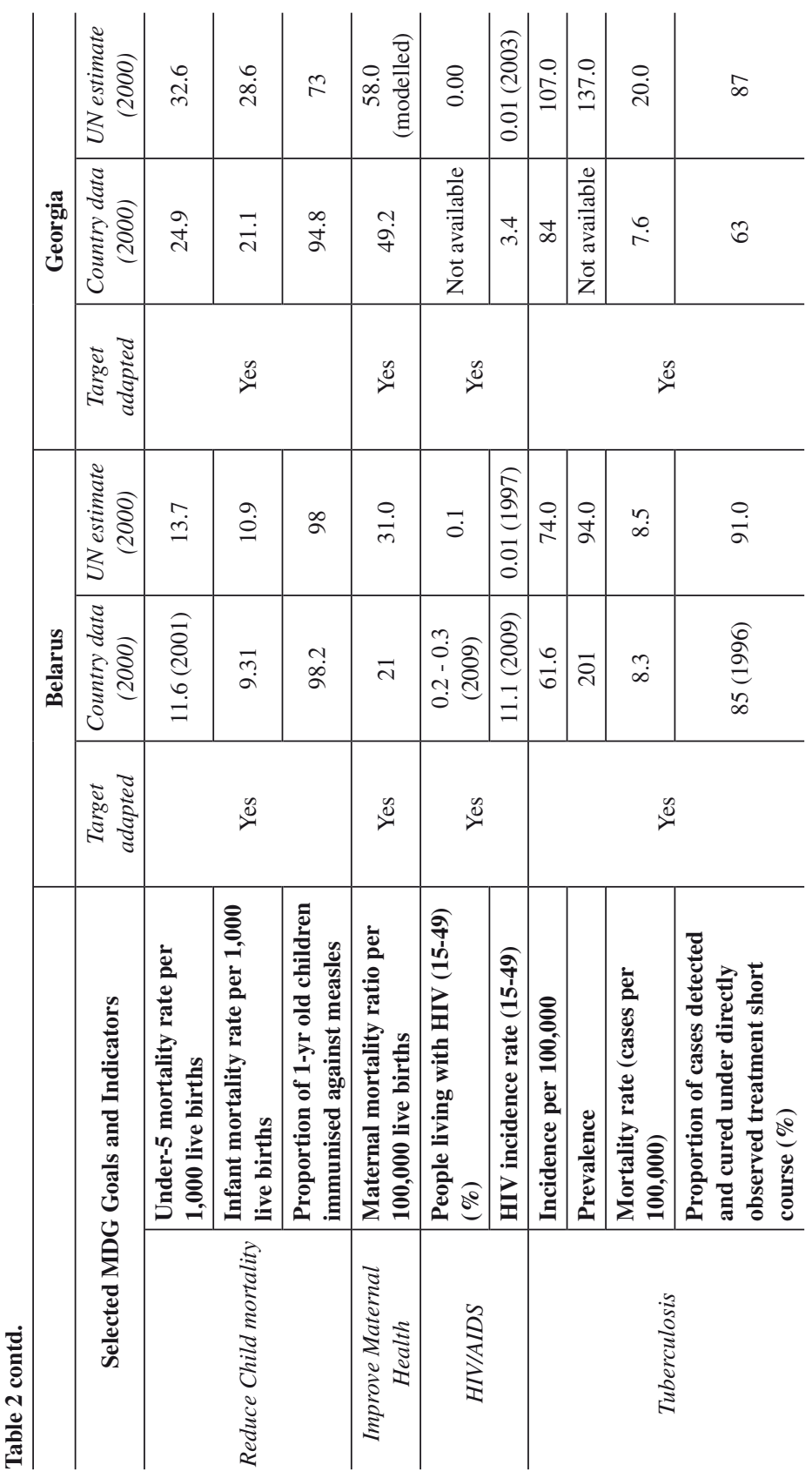




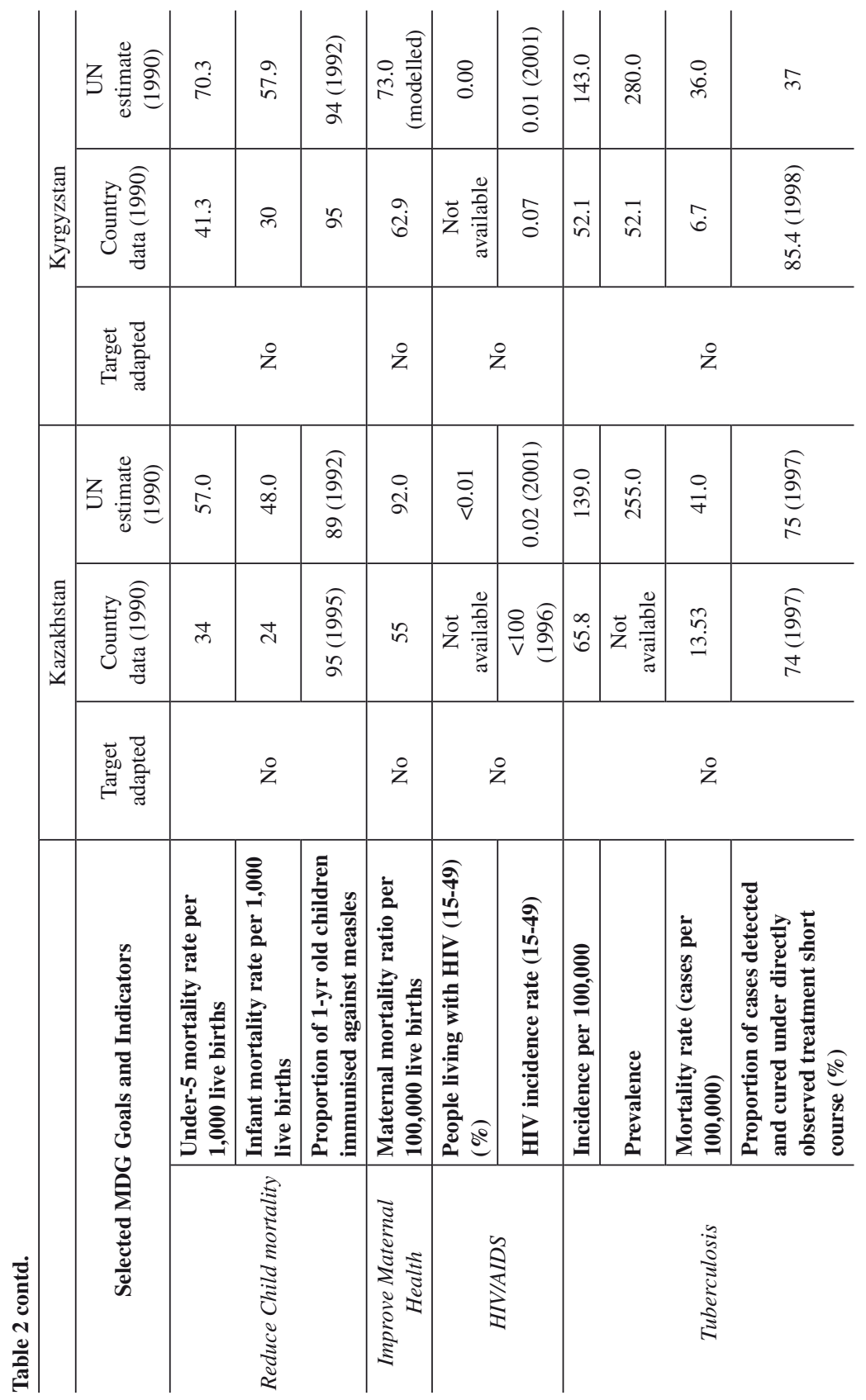




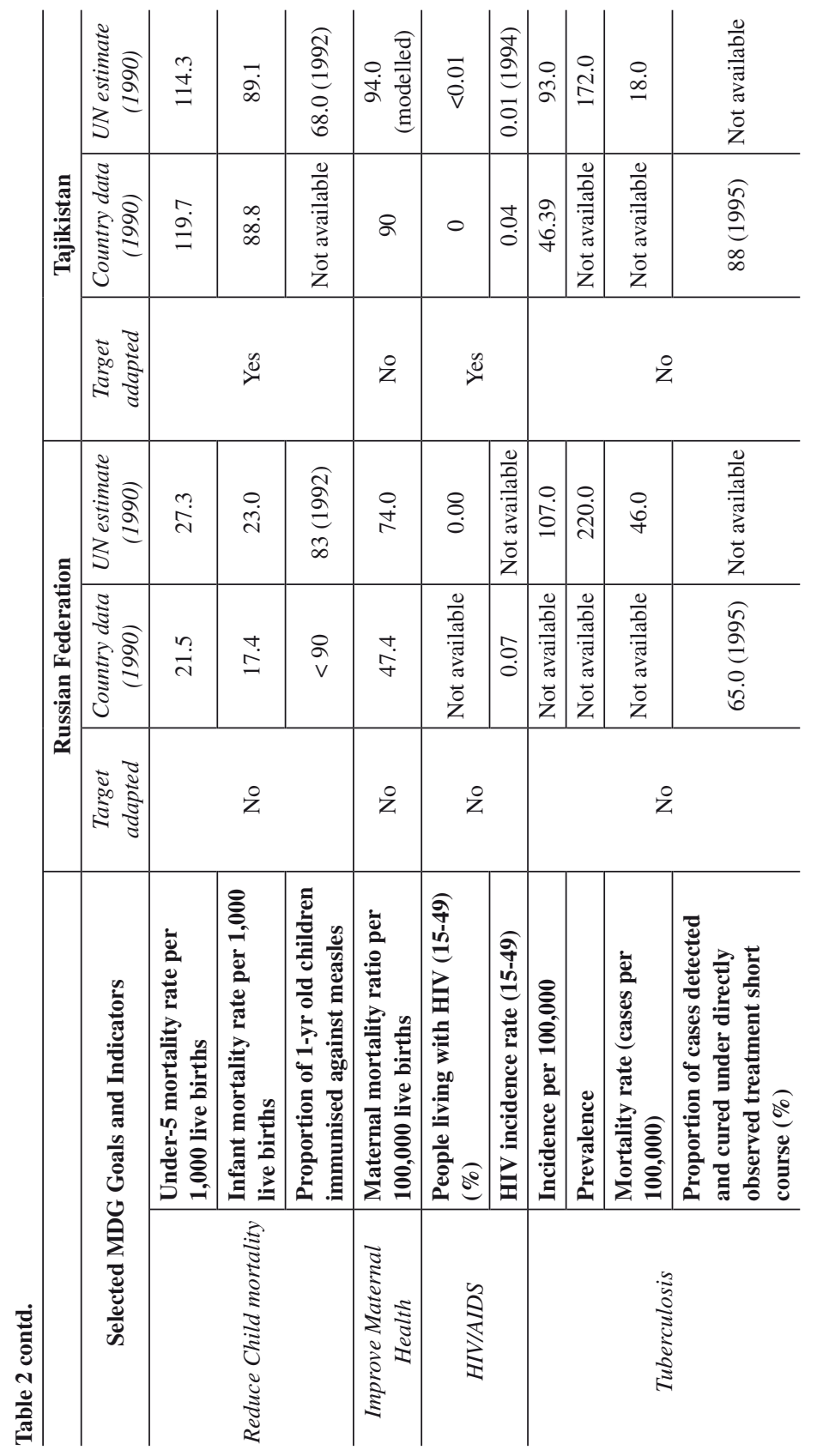




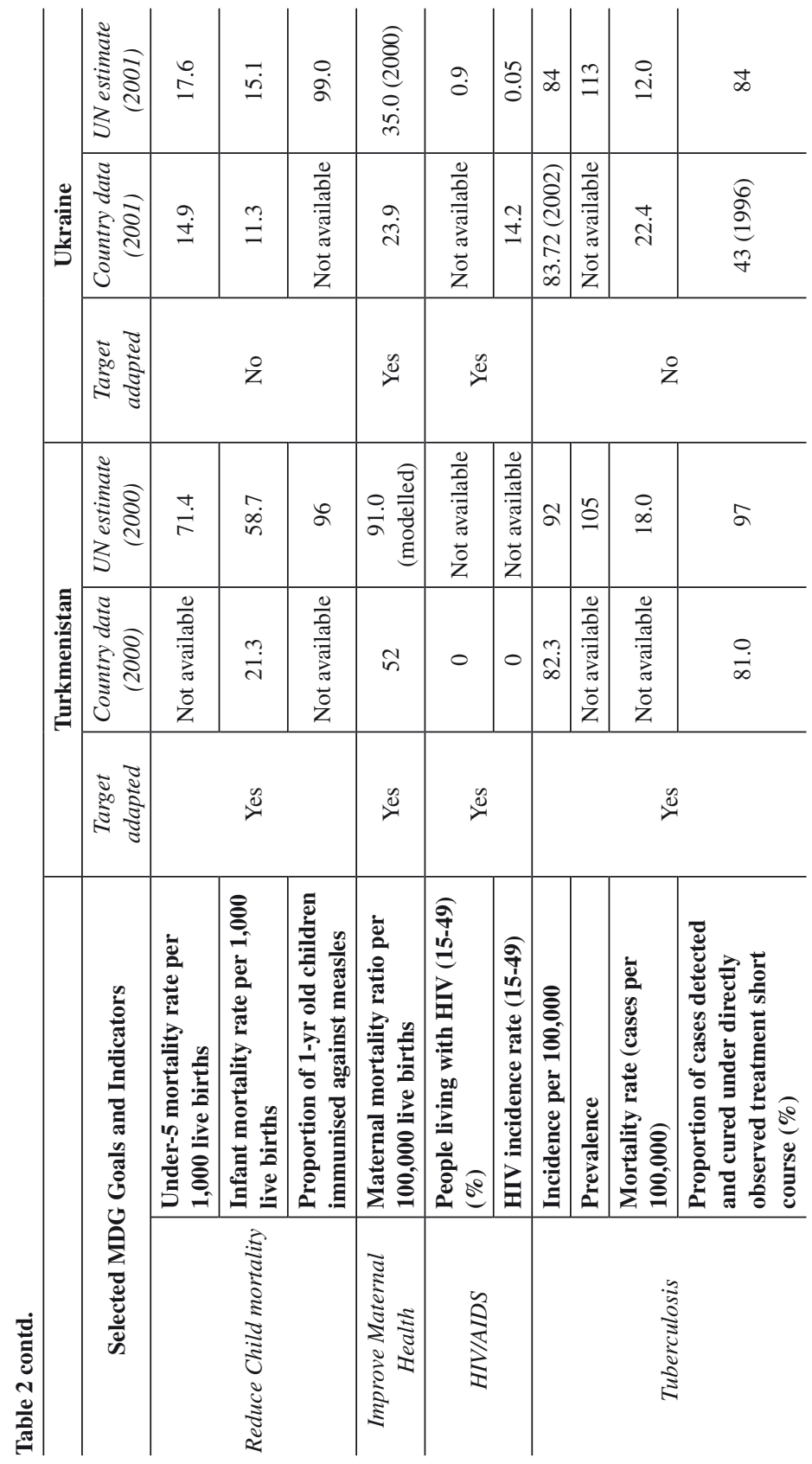




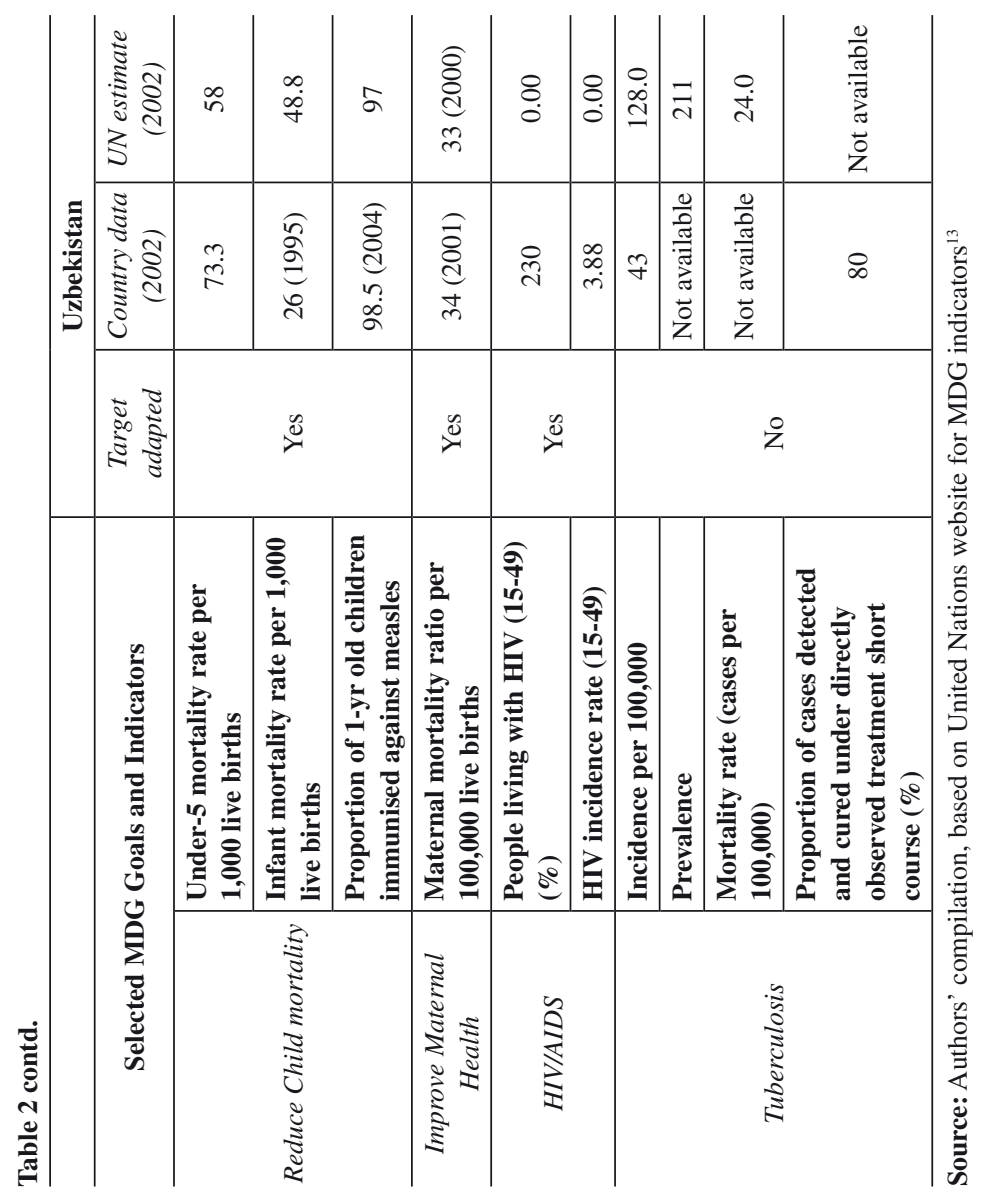


Belarus stands in sharp contrast to most other countries of the region, as it has adopted significantly different targets for child and maternal mortality. The country's child mortality is the lowest among the former Soviet countries (Table 3) and close to rates in Western European countries, so that the related MDG goals are not relevant to Belarus. Instead, the country modified them to: 1) reduce infant morbidity; and 2) reduce under-5 disability prevalence rate. However, no new indicators were introduced to measure these targets.

Russia adopted the MDGs, but clarified that they did not constitute a formal basis for development planning. ${ }^{46,47}$ It aimed to reduce maternal and under-5 mortality by half between 1990 and 2015, rather than by threequarters, as envisaged in the MDGs. ${ }^{46}$ Russia also recognized that premature mortality among the working-age population is the main challenge for national health policy. ${ }^{46}$

\section{A MAJOR CHALLENGE: DATA QUALITY}

As our overview of health-related baselines, goals and indicators within the MDG initiative illustrates, the quality of health data in the former Soviet countries is a major challenge for any meaningful health target-setting. There are significant discrepancies between officially reported data and nationally representative surveys, such as the series of Demographic and Health Surveys and UNICEF's Multiple Indicator Cluster Surveys. Consequently, official data on health indicators vary greatly from estimates by international agencies. Table 3 illustrates these differences with regard to life expectancy, and maternal and infant mortality.

Assuming that international estimates better capture the state of population health, official rates overestimate life expectancy by 5.8 years in Azerbaijan, 5.7 years in Tajikistan and 4.7 years in Kazakhstan. Official data on maternal mortality undercount true rates by 60.1 maternal deaths per 100,000 live births in Turkmenistan, 46.2 maternal deaths in Georgia and 28.2 maternal deaths in Kazakhstan. For infant mortality, official rates undercount actual rates by 37.9 infant deaths per 1000 live births in Tajikistan, 29.2 infant deaths in Azerbaijan and 29.4 infant deaths in Uzbekistan. It is noteworthy that Belarus has the least discrepancies among all three indicators.

What are the reasons behind these discrepancies? Although international reporting criteria, such as the live birth definition of WHO and the International Classification of Diseases, have been adopted by all former Soviet countries, in practice these are not uniformly implemented and the Soviet definition is still often used, leading to an underestimation of infant mortality. ${ }^{33,47,48}$ 


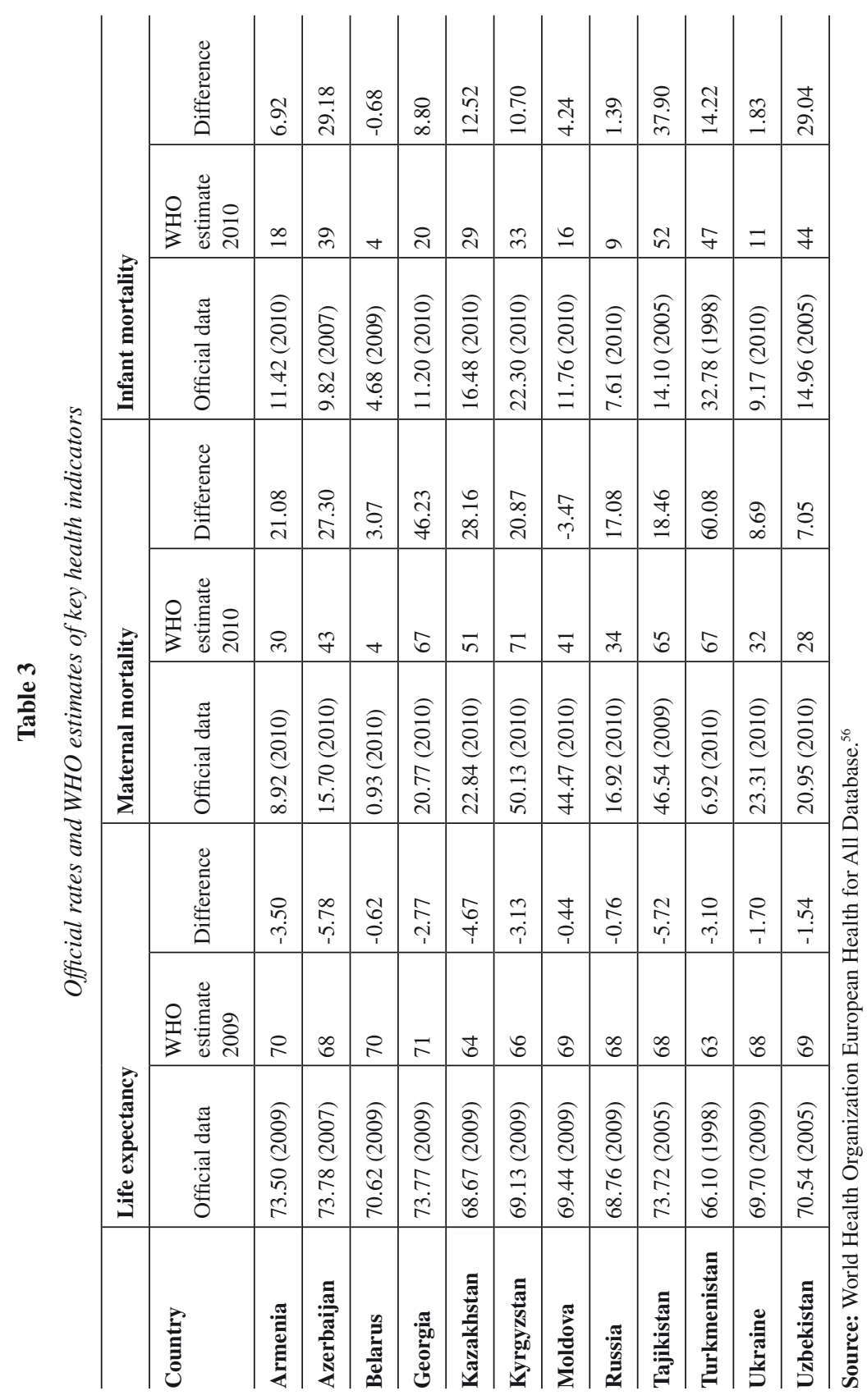


Several more challenges can be identified. First, there is a lack of resources and technical capacity. This is partly due to a lack of training and inadequate access to coding manuals. A more general lack of analytical and statistical training for researchers and decision-makers limits the usefulness of collected data. ${ }^{50}$ Epidemiology and statistical analysis skills are still scarce ${ }^{50}$ Furthermore, in some countries, in particular in Central Asia and the Caucasus, health care facilities in rural regions still lack basic computing IT facilities, leading to the use of error-prone handwritten records. ${ }^{33,51}$

Second, health information systems are often characterized by fragmentation, duplication and other inefficiencies, making it difficult to link data and extract meaningful results. The various data-collection systems and agencies tend to work independently, and fail to coordinate or pool data effectively. ${ }^{33,52}$ The lack of disaggregated epidemiological data is another concern. ${ }^{48}$

Third, anonymity is often not guaranteed. Communicable diseases such as tuberculosis, HIV/AIDS and sexually transmitted infections (STIs) are generally underreported, due to often non-anonymous data collection practices, leading to stigmatization. ${ }^{33,48,53}$

Fourth, the privatization of health care facilities is an issue, as it has not been accompanied by sufficient regulatory measures and the enforcement of mandatory data reporting. In almost all countries of the region, much data collection is limited to the public sector, leading to overall underreporting of a number of indicators.

Finally, there is outright data manipulation. Some facility managers exert pressure to comply with expected outcomes, particularly in infant and maternal health indicators, reminiscent of similar practices during the Soviet period, when failure to meet expectations led to severe punishment. ${ }^{11}$ Concerns with regard to such practices were noted in Azerbaijan and Uzbekistan; in the latter country maternal deaths are considered to have arisen from a criminal offence. ${ }^{48,54}$

\section{CONCLUSION}

This article reviewed two areas of health target-setting in the former Soviet countries: national health strategies and the national targets and indicators used in the context of the UN's MDG initiative. We found that the health targets set out in the majority of national health strategies were not SMART. Only a few countries had embraced quantitative and time-bound health targets. In contrast, measurable and time-bound targets were adopted by almost all countries of the region within the MDG initiative. However, the 
original targets were often adapted and different baselines for indicators used. Furthermore, there were significant discrepancies between officially reported national rates and estimates by international agencies.

National health strategies and national targets embraced within the MDG initiative seemed to be poorly coordinated and aligned. It appears that the setting up of MDG targets was largely externally driven and that there was a lack of coordination between national authorities and international agencies. This is one of the possible explanations for the significant discrepancies between officially reported national rates and estimates by international agencies.

Although the original targets were adapted by almost all countries of the region within the MDG initiative and different baselines for indicators were used, they were still of limited use for guiding national health policies. This is not surprising, as the MDGs failed to reflect the considerable burden of non-communicable disease in the former Soviet countries and were thus of limited use for guiding national health policies. It is abundantly clear that health policies in this region should include a major focus on noncommunicable diseases, such as cardiovascular diseases and external causes of death..$^{55}$

After the identification of health targets based on actual population needs and appropriate indicators to measure progress, it is indispensable to ensure a flawless collection of high-quality data. Yet, data quality emerged as another crucial challenge for meaningful health target-setting in the region. Setting and achieving health targets relies on high quality data and rigorous data management. Systematic collection of accurate, internationally comparable data for subsequent analysis by trained staff is a prerequisite for meaningful evaluation and informed decision making. While this article focussed on population health indicators, other areas of health system governance are also affected. One of these areas is health financing, where widespread informal out-of-pocket payments undermine many health system goals, but are extremely difficult to capture or to eradicate. ${ }^{8}$

Finally, the discrepancies between official country data and those collected or estimated by external agencies are a major cause for concern. Inaccurate data trivialize the scale of health problems and reduce the incentive to invest in health.

Conflicts of Interest: None declared. 


\section{REFERENCES}

1. van Herten LM, Gunning-Schepers LJ. Targets as a tool in health policy: Part I: lessons learned. Health Policy. 2000;53:1-11.

2. Ritsatakis A. Experience in setting targets for health in Europe. Eur J Public Health. 2000;4:7-10.

3. World Health Organization. Targets for Health for All. Copenhagen: WHO, Regional Office for Europe; 1985.

4. Wismar M, McKee M, Ernst K, Srivastava D, Busse R. Introduction. In: Wismar M, McKee M, Ernst K, Srivastava D, Busse R, (editors). Health Targets in Europe - Learning from Experience. World Health Organization on behalf of the European Observatory on Health Systems and Policies; 2008. p.1-6.

5. Wismar M, Busse R. Outcome-related health targets--political strategies for better health outcomes: a conceptual and comparative study (part 2). Health Policy. 59:223-41.

6. Ernst K, Wismar M, Busse R, McKee M. Improving the Effectiveness of Health Targets. Health Targets in Europe - Learning from experience. Copenhagen: European Observatory on Health Systems and Policies; 2008. p.42-9.

7. Smith PC, Busse R. Learning from the European experience of using targets to improve population health. Prev Chronic Dis. 15 August 2010. 7;5:A102. Epub.

8. Rechel B, Roberts B, Richardson E, Shishkin S, Shkolnikov V, et al. Health and health systems in the Commonwealth of Independent States. Lancet. 2013; 381:1145-55.

9. Gotsadze G, Chikovani I, Goguadze K, Balabanova D, McKee M. Reforming sanitary-epidemiological service in Central and Eastern Europe and the former Soviet Union: an exploratory study. BMC Public Health. 2010;10:440.

10. Rechel B, McKee M. Health reform in Central and Eastern Europe and the former Soviet Union. Lancet. 2009;374:1186-95.

11. Danishevski K. The Russian Federation: Difficult History of Target Setting. In: Wismar M, McKee M, Ernst K, Srivastava D, Busse R, (editors). Health Targets in Europe - Learning from experience. World Health Organization on behalf of the European Observatory on Health Systems and Policies; 2008.

12. McKee M, Zwi A, Koupilova I, Sethi D, Leon D. Health policy-making in Central and Eastern Europe: lessons from the inaction on injuries? Health Policy Plan. 2000;15:263-9.

13. United Nations. Millenium Development Goals Indicators- The official United Nations site for the MDG indicators 2013. Available from URL: www.mdgs. un.org (Accessed 8 April 2013).

14. Muller JE, Abdellah FG, Billings FT, Hess AE, Petit D, Egeberg RO. The Soviet health system--aspects of relevance for medicine in the United States. N Engl J Med. 1972;286:693-702.

15. Field MG. Doctor and Patient in Soviet Russia. Cambridge (MA): Harvard University Press; 1957. p.14-9. 
16. Glass RI. The SANEPID Service in the USSR. Public Health Rep. 1976;91:1548.

17. Ryan M, Stephen J. General practitioners and family doctors in the Russian Federation. Br J Gen Pract. 1996;46:487-9.

18. Sigerist H. Socialized Medicine in the Soviet Union. New York (NY): Norton; 1937.

19. Healy J, McKee M. Implementing hospital reform in Central and Eastern Europe. Health Policy. 2002;61:1-19.

20. Field MG. The position of the Soviet physician: the bureaucratic professional. Milbank Q. 1988;66 (2 Suppl):182-201.

21. Ryan M. The organization of Soviet Medical Care. Oxford: Basil Blackwell; 1978.

22. Tulchinsky T, Varavikova E. Addressing the epidemiologic transition in the former Soviet Union: strategies for health system and public health reform in Russia. Am J Public Health. 1996;86:313-20.

23. Barr DA, Field MG. The current state of health care in the former Soviet Union: implications for health care policy and reform. Am J Public Health. 1996;86: 307-12.

24. Hill SR Jr. Medicine in the Union of Soviet Socialist Republics. Trans Am Clin Climatol Assoc. 1984;95:163-9.

25. McKee M. Cochrane on Communism: the influence of ideology on the search for evidence. Int J Ep idemiol. 2007;36:269-73.

26. Andreev EM, Nolte E, Shkolnikov VM, Varavikova E, McKee M. The evolving pattern of avoidable mortality in Russia. Int J Epidemiol. 2003;32:437-46.

27. Davis C. Rising Infant Mortality in the USSR in the 1970s. Washington (DC): United States Department of Commerce; 1980.

28. Schultz DS, Rafferty MP. Soviet health care and perestroika. Am J Public Health. 1990;80:193-7.

29. Anderson BA, Silver BD. Trends in mortality of the Soviet population. Sov Econ. 1990;6:191-251.

30. Omran AR. The epidemiologic transition: a theory of the epidemiology of population change. 1971. Milbank Q. 2005;83:731-57.

31. Rowland D, Telyukov AV. Soviet health care from two perspectives. Health Aff (Millwood) 1991;10:71-86.

32. Maier C, Martin-Moreno J. Quo vadis SANEPID? A cross-country analysis of public health reforms in 10 post-Soviet states. Health Policy. 2011;102:1825.

33. Khodjamurodov G, Rechel B. Tajikistan: health system review. Health Syst Transit. 2010;12:v-xix, 1-154.

34. Katsaga A, Kulzhanov M, Karanikolos M, Rechel B. Kazakhkstan health system review. Health Syst Transit. 2012;14:1-154.

35. United Nations. United Nations Millennium Declaration 2000. Available from URL: http://www.un.org/millennium/declaration/ares552e.htm (Accessed 8 April 2013). 
36. United Nations. Millenium Development Goals Indicators - The official United Nations site. The MDG Indicators 2013. Available from URL: http://mdgs. un.org/unsd/mdg/ (Accessed 8 April 2013).

37. Government of Armenia, Armenia UNCTi. Armenia: MDG National Progress Report. 2010.

38. Singer H. Millenium Development Goals in Kazakhstan. Astana: United Nations; 2010.

39. Skuratowicz J. The Kyrgyz Republic - Millennium Development Goals Progress Report. Bishkek: United Nations; 2003.

40. Secretariat of State Programme on Poverty Reduction and Economic Development, Azerbaijan U. Azerbaijan: Where East Meets the West - MDG Progress Report to the 2005 World Summit. 2005.

41. Government of Georgia, Georgia UNCTU. Millennium Development Goals in Georgia: Progress Report for 2004-2005. Tbilisi: 2005.

42. Government of Moldova, Moldova UNA. The Second Millennium Development Goals Report - Republic of Moldova. 2010.

43. Government of Turkmenistan. Millennium Development Goals Report: Turkmenistan. Ashghabat: 2003.

44. Government of Ukraine, Ukraine UNAi. Millennium Development Goals Ukraine 2010 National Report. Kiev: 2010.

45. United Nations Country Team. Millennium Development Goals Report. Taschkent: 2006.

46. United Nations Development Programme. Millennium Development Goals in Russia: Looking into the Future. Moscow: UNDP; 2010.

47. Popovich L, Potapchik E, Shishkin S, Richardson E, Vacroux A, Mathivet B. Russian Federation: Health system review. Health Syst Transit. 2011;13:1190.

48. Ahmedov M, Azimov R, Alimova V, Rechel B. Uzbekistan - Health system review. World Health Organization on behalf of the European Observatory on Health Systems and Policies; 2007.

49. Katsaga A, Kehler J. WHO mission to evaluate the quality of data for the purpose of assessing health system performance. Baku: World Health Organization Regional Office for Europe; 2008.

50. Vlassov V. Is there epidemiology in Russia? J Epidemiol Community Health. 2000;54:740-4.

51. Hakobyan T, Nazaretyan M, Makarova T, Aristakesyan M, Margaryants H, Nolte E. Armenia Health System Review. Yerevan: European Observatory on Health Systems and Policies; 2006.

52. Turcanu G, Domente S, Buga M, Richardson E. Republic of Moldova Health System Review. 2012.

53. Bernitz BL, Rechel B. HIV data in Central and Eastern Europe: fact or fiction? In: Matic S, Lazarus JV, Donoghoe MC, (editors). HIV/AIDS in Europe Moving from Death Sentence to Chronic Disease Management. Copenhagen: World Health Organization Regional Office for Europe; 2006. p.232-42. 
54. Ibrahimov F, Ibrahimova A, Kehler J, Richardson E. Azerbaijan: health system review. Health Syst Transit. 2010;12:1-115.

55. Rechel B, Shapo L, McKee M, Health NaPG, Europe and Central Asia Region, World Bank. Are the health Millennium Development Goals appropriate for Eastern Europe and Central Asia? Health Policy. 2005;73:339-51. 